\title{
Inbreeding and the genetic variance in floral traits of Mimulus guttatus
}

\author{
JK Kelly and HS Arathi \\ Department of Ecology and Evolutionary Biology, University of Kansas, 1200 Sunnyside Avenue, Lawrence KS 66045-7534, USA
}

\begin{abstract}
The additive genetic variance, $V_{\mathrm{A}}$, is frequently used as a measure of evolutionary potential in natural plant populations. Many plants inbreed to some extent; a notable observation given that random mating is essential to the model that predicts evolutionary change from $V_{\mathrm{A}}$. With inbreeding, $V_{\mathrm{A}}$ is not the only relevant component of genetic variation. Several nonadditive components emerge from the combined effects of inbreeding and genetic dominance. An important empirical question is whether these components are quantitatively significant. We use maximum likelihood
\end{abstract}

estimation to extract estimates for $V_{\mathrm{A}}$ and the nonadditive 'inbreeding components' from an experimental study of the wildflower Mimulus guttatus. The inbreeding components contribute significantly to four of five floral traits, including several measures of flower size and stigma-anther separation. These results indicate that inbreeding will substantially alter the evolutionary response to natural selection on floral characters.

Heredity (2003) 90, 77-83. doi:10.1038/sj.hdy.6800181

Keywords: additive variance; heritability; inbreeding; Mimulus guttatus; quantitative genetics

\section{Introduction}

The additive variance, $V_{\mathrm{A}}$, is the principal statistic of quantitative genetics. While no single quantity can fully describe the complexities of multi-locus inheritance, $V_{\mathrm{A}}$ is a remarkable abstraction. It is a primary determinant of the resemblance of relatives and also provides a measure of the capacity for a trait to evolve in response to selection. Estimates of $V_{\mathrm{A}}$ can be used to predict evolutionary change quantitatively (eg Clayton et al, 1957; Grant and Grant, 1995) or, more frequently, as measures of the evolutionary potential in a given trait. Random mating is critical to these applications (MitchellOlds and Rutledge, 1986; Wright, 1987; Kelly, 1999a). If a population does not mate randomly, particularly if it inbreeds to some extent, the sufficiency of $V_{\mathrm{A}}$ as a measure of evolutionary potential is subject to question.

With random mating, the genetic variance of a quantitative character can be decomposed into three components (Falconer, 1989): the additive variance, the dominance variance $\left(V_{\mathrm{D}}\right)$, and the interaction or epistatic variance $\left(V_{\mathrm{I}}\right)$. There are hundreds of estimates of $V_{\mathrm{A}}$ for morphological, physiological, behavioral, and life history traits within a broad range of organisms (Mousseau and Roff, 1987). In contrast, $V_{\mathrm{D}}$ and $V_{\mathrm{I}}$ are frequently neglected in empirical studies. In part, this is because of difficulties associated with their estimation (Bridges and Knapp, 1987; Fenster et al, 1997). However, the scarcity of estimates probably also reflects a perception that nonadditive components are irrelevant to the evolutionary process (Wade, 1992; Brodie, 2000).

Correspondence: JK Kelly, Department of Ecology and Evolutionary Biology, University of Kansas, 1200 Sunnyside Avenue, Lawrence KS 66045-7534, USA. E-mail: jkk@ku.edu
Nonadditive components make a demonstrable contribution to evolutionary change in inbreeding populations (Pederson, 1969; Cockerham and Matzinger, 1985). The increased homozygosity caused by inbreeding complicates the decomposition of the genetic variance (Robertson, 1952; Harris, 1964; Gillois, 1964). Even in the absence of epistasis, the genetic variance depends not only on $V_{\mathrm{A}}$ and $V_{\mathrm{D}}$, but also the covariance of additive and dominance effects $\left(C_{\mathrm{AD}}\right)$, the homozygous or inbreeding dominance variance $\left(V_{\mathrm{DI}}\right)$, and the sum of squared inbreeding depression effects across loci $\left(H^{*}\right)$. While there are a number of alternative formulations (reviewed in Cornelius, 1988; de Boer and Hoeschele, 1993), we use Cockerham's (1983) decomposition of the genetic variance. Our symbols $V_{\mathrm{A}}, V_{\mathrm{D}}, C_{\mathrm{AD}}, V_{\mathrm{DI}}$, and $H^{*}$ correspond to $\sigma_{\mathrm{A}}^{2}, \sigma_{\mathrm{D}}^{2}, D_{1}, D_{2}$, and in Cockerham (1983).

An important empirical question is whether the inbreeding components $\left(C_{\mathrm{AD}}, V_{\mathrm{DI}}\right.$, and $\left.H^{*}\right)$ are quantitatively important. Are $C_{\mathrm{AD}}, V_{\mathrm{DI}}$, and $H^{*}$ comparable in magnitude to $V_{\mathrm{A}}$ ? If alleles are nearly additive in their effects, the inbreeding components will be small relative to $V_{\mathrm{A}}$. Under these conditions, a model based on $V_{\mathrm{A}}$ alone can yield accurate predictions of evolutionary change even with high levels of inbreeding (Kelly and Williamson, 2000). If dominance is substantial, however, the model based on $V_{\mathrm{A}}$ can be very inaccurate.

Like the additive variance, the inbreeding components can be estimated from the resemblance of relatives. While the necessary theory has been available for some time, the number of estimates is quite limited (see Gallais, 1977; Cornelius, 1988; Shaw et al, 1998; Shaw and Woolliams, 1999; Abney et al, 2000). Here, we add to this limited collection of estimates with a study of five floral characters of the partially self-fertilizing wildflower Mimulus guttatus. The measurements are derived from a breeding experiment using a large, random collection 
of inbred lines as parents. This experimental design has the advantage of producing family types with high levels of genetic relatedness but differing levels of inbreeding. This greatly increases statistical power and allows estimation of seven distinct variance components for each trait.

\section{Methods}

We used highly inbred lines as parents in a breeding design. John $\mathrm{H}$ Willis initiated over 1000 independent lines of M. guttatus in August 1995. Each line was identified from the seed set of a separate field-collected plant from Iron Mountain (a detailed description of this population can be found in Willis $(1993,1996))$. Each line was subsequently maintained in the greenhouse by single seed descent (self-fertilization) for six generations. Of these sixth generation lines, 300 were used in this study. Each line was randomly assigned to a group with two other lines. Of the three lines in each group, one was randomly selected as sire and the other two as dams. A single plant from the sire line was grown to maturity, self-fertilized, and used as a pollen source for a single plant from each of the dam lines. Each of the dams was also self-fertilized. Five distinct progeny families, labeled A-E, were derived from these crosses (Figure 1). Families A and B are outbred whereas C, D, and E are inbred. We refer to the entire collection $(\mathrm{A}-\mathrm{E})$ of plants derived from a specific set of three lines as an extended family. There were 100 extended families in total.

A maximum of eight pots were seeded per family (40 per extended family) on 9 March 2001 in the University of Kansas greenhouses. As some families were short of seed, the total number of pots was approximately 3400 . At 2 weeks after seeding, all pots were thinned to a single plant (randomly selected) and were subsequently fertilized weekly. Four morphological measurements were taken on the first flower produced by each plant: corolla width, corolla length, pistil length, and anther length. Stigma-anther separation is calculated as the difference

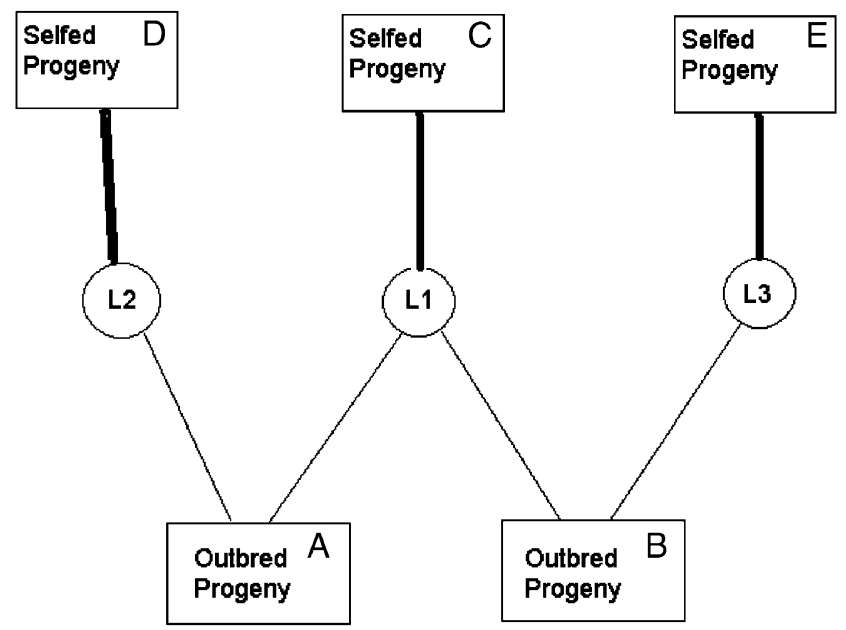

Figure 1 The relationships among family types (A-E) derived from a particular set of lines (L1, L2, and L3). Thick lines denote families derived from self-fertilization while thin lines represent the contribution of a single gamete. Of the three parental lines, L1 is the Sire for outbred families A and B, while L2 and L3 are Dams (for families $B$ and $C$, respectively). between the latter two measurements. This difference is analyzed instead of anther lengths. The date of first flower is included as a fifth measurement. Flowering was monitored daily until 60 days post-seeding, by which time the great majority of plants had flowered. In total, 2345 plants were measured (1113 outbred and 1232 inbred). As a result of germination failure or failure to flower, the distribution of plants across families was not balanced. Many extended families were completely missing one or more of their component families (A-E).

Inbreeding generally changes the mean of a trait in a population, as well as the variance. Following Wright (1951), we can write the mean phenotype, $\bar{Z}$, as a linear function of $F$, the average inbreeding coefficient:

$$
\bar{Z}=M_{\mathrm{O}}+F\left(M_{\mathrm{I}}-M_{\mathrm{O}}\right)
$$

where $M_{\mathrm{O}}$ is the outbred mean and $M_{\mathrm{I}}$ is the inbred mean (the mean phenotype of a population with $F=1$ ). The difference $\left(M_{\mathrm{I}}-M_{\mathrm{O}}\right)$ is frequently referred to as the 'directional dominance' or 'inbreeding depression' of the trait. Here, we define $\beta=M_{\mathrm{I}}-M_{\mathrm{O}}$. With strictly additive inheritance, $\beta=0$.

Variance components are estimated from the resemblance of relatives. There are four different kinds of genetic relationship in this design (Figure 1). The resemblance between individuals within outbred families (A or B) provides an estimate of the genetic covariance between outbred full sibs $\left(C_{\mathrm{fs}}\right)$. The resemblance between individuals within inbred families (C, D, or E) provides an estimate of the genetic covariance between inbred sibs $\left(C_{\mathrm{ss}}\right)$. A comparison between individuals in different outbred families from the same extended family ( $\mathrm{A} v s \mathrm{~B}$ ) provides an estimate of the genetic covariance of outbred half-sibs $\left(C_{\mathrm{hs}}\right)$. Finally, there are a number of different comparisons between inbred and outbred individuals related through a single parent ( $\mathrm{A}$ vs $\mathrm{C}, \mathrm{B}$ vs $\mathrm{C}, \mathrm{A}$ vs $\mathrm{D}$, and $\mathrm{B}$ vs $\mathrm{E}$ ). As these comparisons are equivalent from a genetic point of view, we denote this genetic covariance as $C_{\text {os }}$ (here we are referring to autosomal inheritance only, see below).

Each of these covariances can be expressed as a function of genetic parameters. The quantitative relationships between phenotypic and genetic statistics depend on the inbreeding coefficient $(F)$ of the parents. Our parental generation was sixth generation selfed and their inbreeding coefficient is $1-(0.5)^{6}=0.984$. We can thus treat the parents as completely inbred $(F=1)$ to a good approximation. Using this value for $F$ with the equations in Cockerham and Weir (1984), we obtain the following relations:

$$
\begin{aligned}
& C_{\mathrm{hs}}=\frac{1}{2} V_{\mathrm{A}} \\
& C_{\mathrm{fs}}=V_{\mathrm{A}}+V_{\mathrm{D}} \\
& C_{\mathrm{ss}}=2 V_{\mathrm{A}}+4 C_{\mathrm{AD}}+V_{\mathrm{DI}} \\
& C_{\mathrm{os}}=V_{\mathrm{A}}+C_{\mathrm{AD}}
\end{aligned}
$$

The component $H^{*}$ does not contribute to these covariances and is not estimated here. For the special case of two alleles per locus, $H^{*}=V_{\mathrm{D}}$ (Cockerham and Weir, 1984).

We also distinguish and estimate three different environmental sources of variation in each trait. Maternal 
effects are a potentially important source of resemblance among relatives. We assume that all individuals from the same maternal plant share a common maternal effect with variance $V_{\mathrm{M}}$. Maternal effects can be distinguished from genetic sources of covariance by comparing sets of individuals with equivalent genetic relationships but differing maternal relationships. An individual in family A has the same genetic covariance with an individual in either family $C$ or family $D$ (Figure 1 ), but the $A-C$ relationship is through a male parent while the $A-D$ relationship is through a female. Maternal effects will elevate the latter covariance but not the former. As defined in this way, the maternal effect will include maternally inherited (cytoplasmic) genetic factors (eg Beavis and Frey, 1987; Galloway and Fenster, 2001) and even noncytoplasmic maternal effects may be heritable (see Willham, 1963).

A preliminary inspection of the data suggested higher variances within inbred families than within outbred families. Since all individuals within a family are genetically identical (or very nearly so), this must be owing to differing levels of environmental sensitivity. We thus include two different environmental variances in our model: $V_{\mathrm{E}(\mathrm{o})}$ is the environmental variance for outbred individuals and $V_{\mathrm{E}(\mathrm{i})}$ is the environmental variance for inbred individuals.

\section{Analysis and Results}

Maximum likelihood was used to estimate $M_{\mathrm{O}}$ and $\beta$ (as fixed effects) and the variance components for each trait (Shaw, 1987). Prior to extraction of variance components, we applied (Wright 1952) first two criteria to insure that each trait was measured on a proper scale. The first criterion is that the level of variation within inbred lines and within F1 families should be as uniform as possible. The second criterion is that the distribution of each character should be approximately normal within both inbred and outbred samples. We were generally unable to find a scale transformation that fully satisfied the first criterion (see below), so we applied the somewhat weaker condition that the variance within families (either outbred or inbred) should be uncorrelated with the family mean value for a particular trait.

We found that pistil length, stigma-anther separation, and flower length satisfied these conditions, at least approximately, on their original scale of measurement.
A square root transformation was necessary for corolla width. The distribution of the number of days to first flower was highly right-skewed on the original scale. To achieve both normality and homoscedasticity, we subtracted 23 from day of flower (the first plants flowered on day 24) and then applied a logarithmic transformation to the difference. The means and standard deviations (SD) among outbred and inbred plants for each trait are given in Table 1.

Estimates were obtained by finding the set of values for $M_{\mathrm{O}}, \beta, V_{\mathrm{A}}, V_{\mathrm{D}}, C_{\mathrm{AD}}, V_{\mathrm{DI}}, V_{\mathrm{M}}, V_{\mathrm{E}(\mathrm{o})}$ and $V_{\mathrm{E}(\mathrm{i})}$ that maximize 1, the log likelihood of the model given the data:

$$
l=C-\frac{1}{2} \ln |V|-\frac{1}{2}(z-X \eta)^{\mathrm{T}} V^{-1}(z-X \eta)
$$

where $V$ is the variance-covariance matrix of individual measurements, $z$ is the vector of trait values, $X$ is an 'incidence matrix' for fixed effects, $\eta$ is the vector of fixed effects, and $C$ is a constant determined by the total sample size (Shaw, 1987). In this application, the variance components $\left(V_{\mathrm{A}}, V_{\mathrm{D}}, C_{\mathrm{AD}}, V_{\mathrm{DI}}, V_{\mathrm{M}}, V_{\mathrm{E}(\mathrm{o})}\right.$ and $\left.V_{\mathrm{E}(\mathrm{i})}\right)$ determine the numerical values of elements in $V$ and $\eta=\left[M_{\mathrm{O}}, \beta\right]^{\mathrm{T}}$. The maximization is subject to the constraints that (1) $V_{\mathrm{E}(\mathrm{o})}$ and $V_{\mathrm{E}(\mathrm{i})}$ must be positive; (2) $V_{\mathrm{M}}$, $V_{\mathrm{A}}, V_{\mathrm{D}}$, and $V_{\mathrm{DI}}$ must be greater than or equal to zero; and (3) $C_{\mathrm{AD}}$ is constrained in absolute value by $V_{\mathrm{A}}$ and $V_{\text {DI }}$. For each set of parameters, we also evaluated the first derivatives of the log likelihood (equation (3)) with regard to each parameter and the asymptotic dispersion matrix (Searle et al, 1992, ch. 6; Eliason, 1993). These were subsequently used to find the maximum iteratively by the method of scoring (Searle et al, 1992, ch. 8; Shaw and Woolliams, 1999).

The numerical evaluation of equation (3), as well as the derivates and dispersion matrix, was greatly simplified by the structure of the data. Since each extended family is unrelated to other extended families, $V$ assumes a blockdiagonal form (with one block corresponding to each extended family). This allows calculation of equation (3) from the determinants and inverses of each block. The program to conduct these calculations was written in $\mathrm{C}$ and executed on a Dell 410 workstation. As a result of the block-diagonal form of $V$, a complete iteration requires only seconds of computer time. Estimation programs for inbreeding variance components that can accommodate more general data structures have been developed by Shaw et al (1998), Shaw and Woolliams (1999), and Abney et al (2000).

Table 1 Means and SD of each trait are given for both outbred and inbred plants in columns 1-4

\begin{tabular}{|c|c|c|c|c|c|}
\hline Trait & Outbred mean & Outbred SD & Inbred mean & Inbred SD & $\beta$ \\
\hline 1. Sqrt (corolla width) & 4.38 & 0.31 & 4.16 & 0.36 & $\begin{array}{r}-0.69 \\
(0.07)\end{array}$ \\
\hline 2. Pistil length & 14.7 & 1.33 & 13.8 & 1.61 & $\begin{array}{r}-0.63 \\
(0.06)\end{array}$ \\
\hline 3. Stigma-anther separation & 2.49 & 0.95 & 2.69 & 1.15 & $\begin{array}{c}0.12 \\
(0.06)\end{array}$ \\
\hline 4. Flower length & 22.6 & 2.62 & 21.0 & 2.93 & $\begin{array}{r}-0.61 \\
(0.05)\end{array}$ \\
\hline 5. Ln (days to anthesis -23 ) & 2.64 & 0.40 & 2.82 & 0.38 & $\begin{array}{c}0.51 \\
(0.06)\end{array}$ \\
\hline
\end{tabular}

The units are $\mathrm{mm}$ for traits $2-4, \sqrt{ } \mathrm{mm}$ for trait 1 , and $\mathrm{Ln}$ (days) for trait 5 . The last column is the estimated directional dominance, $\beta$, of each trait (with SE) obtained from the ML procedure. $\beta$ is expressed in units of outbred phenotypic standard deviations (see text) and is statistically nonzero for each trait. 
Table 2 Maximum likelihood estimates for each trait with standard errors (in parentheses) derived from asymptotic dispersion matrices

\begin{tabular}{|c|c|c|c|c|c|c|c|}
\hline Trait & $V_{\mathrm{A}}$ & $V_{\mathrm{D}}$ & $C_{\mathrm{AD}}$ & $V_{\mathrm{DI}}$ & $V_{\mathrm{E}(\mathrm{o})}$ & $V_{\mathrm{E}(\mathrm{i})}$ & $V_{\mathrm{M}}$ \\
\hline 1. Sqrt (corolla width) & $\begin{array}{c}0.25 \\
(0.09)\end{array}$ & $\begin{array}{c}0.00 \\
(0.09)\end{array}$ & $\begin{array}{c}-0.09 \\
(0.09)\end{array}$ & $\begin{array}{c}0.38 \\
(0.19)\end{array}$ & $\begin{array}{c}0.62 \\
(0.03)\end{array}$ & $\begin{array}{c}0.73 \\
(0.04)\end{array}$ & $\begin{array}{c}0.12 \\
(0.06)\end{array}$ \\
\hline 2. Pistil length & $\begin{array}{c}0.24 \\
(0.09)\end{array}$ & $\begin{array}{c}0.06 \\
(0.08)\end{array}$ & $\begin{array}{c}0.01 \\
(0.08)\end{array}$ & $\begin{array}{c}0.20 \\
(0.17)\end{array}$ & $\begin{array}{c}0.61 \\
(0.03)\end{array}$ & $\begin{array}{c}0.65 \\
(0.03)\end{array}$ & $\begin{array}{c}0.10 \\
(0.07)\end{array}$ \\
\hline 3. Stigma-anther separation & $\begin{array}{c}0.36 \\
(0.09)\end{array}$ & $\begin{array}{c}0.07 \\
(0.07)\end{array}$ & $\begin{array}{c}0.02 \\
(0.07)\end{array}$ & $\begin{array}{c}0.27 \\
(0.16)\end{array}$ & $\begin{array}{c}0.57 \\
(0.03)\end{array}$ & $\begin{array}{c}0.73 \\
(0.03)\end{array}$ & $\begin{array}{l}0.0 \\
(0.07)\end{array}$ \\
\hline 4. Flower length & $\begin{array}{c}0.11 \\
(0.07)\end{array}$ & $\begin{array}{c}0.01 \\
(0.08)\end{array}$ & $\begin{array}{c}0.01 \\
(0.07)\end{array}$ & $\begin{array}{c}0.12 \\
(0.16)\end{array}$ & $\begin{array}{c}0.67 \\
(0.03)\end{array}$ & $\begin{array}{c}0.71 \\
(0.03)\end{array}$ & $\begin{array}{c}0.21 \\
(0.06)\end{array}$ \\
\hline 5. Ln (age at first flower -23 ) & $\begin{array}{c}0.32 \\
(0.11)\end{array}$ & $\begin{array}{c}0.14 \\
(0.09)\end{array}$ & $\begin{array}{r}-0.10 \\
(0.10)\end{array}$ & $\begin{array}{c}0.21 \\
(0.19)\end{array}$ & $\begin{array}{c}0.50 \\
(0.03)\end{array}$ & $\begin{array}{c}0.44 \\
(0.02)\end{array}$ & $\begin{array}{c}0.04 \\
(0.06)\end{array}$ \\
\hline
\end{tabular}

Estimates are given in standardized units $\left(V_{\mathrm{A}}+V_{\mathrm{D}}+V_{\mathrm{E}(\mathrm{o})}+V_{\mathrm{M}}=1\right.$ for each trait). Significant likelihood ratio tests are indicated with bold type (see text for details of hypothesis testing).

We used the likelihood ratio method to test six distinct null hypotheses: (1) $V_{\mathrm{M}}=0$; (2) $V_{\mathrm{E}(\mathrm{i})}=V_{\mathrm{E}(\mathrm{o})}$; (3) $V_{\mathrm{D}}=0$; (4) $C_{\mathrm{AD}}=0$; (5) $C_{\mathrm{AD}}=0$ and $V_{\mathrm{DI}}=0$; (6) $C_{\mathrm{AD}}=0$ and $V_{\mathrm{A}}=0$. Hypotheses $1-4$ reduce the likelihood model by a single parameter. Hypotheses 4 and 5 reduce the likelihood model by two parameters because $C_{\mathrm{AD}}$ must be 0 whenever $V_{\mathrm{DI}}=0$ or $V_{\mathrm{A}}=0$ (Shaw et al, 1998). Hypotheses 1-6 were tested in order. If a parameter proved nonsignificant (by the method described below), it was eliminated from the model for subsequent tests. Each null hypothesis was tested by comparing the maximum likelihood obtained under that hypothesis (eg $C_{\mathrm{AD}}=0$ ) to the maximum likelihood obtained from the model including that parameter. The null hypothesis was rejected (at $P<0.05)$ if $2\left(l_{1}-l_{0}\right)$ was greater than the appropriate critical value, where $l_{0}$ represents the logarithm of the maximum likelihood obtained under the null hypothesis and $l_{1}$ denotes the corresponding value for the model that includes the parameter. It is generally assumed that $2\left(l_{1}-l_{0}\right)$ follows a $\chi^{2}$ distribution under the null hypothesis with the number of degrees determined by the number of parameters fixed under that hypothesis (Rice, 1988, ch. 9). The usual critical value of 3.84 (from the $\chi^{2}$ distribution with a single degree of freedom) was used for hypotheses 2 and 4 . However, because $V_{\mathrm{D}}$ and $V_{\mathrm{M}}$ are constrained to nonnegative values even under the null hypothesis, a critical value of 2.7 is more appropriate (Self and Liang, 1987; Shaw et al, 1998).

Estimates of the genetic parameters for each trait and associated statistical tests are presented in Table 2. An approximate standard error (given in parentheses) was obtained for each estimate from the asymptotic dispersion matrix. As the data are amenable to resampling, we also performed a delete-10 Jack-knife over extended families to obtain a second set of standard errors. The Jack-knife standard errors were comparable to, but generally smaller than, the values from the dispersion matrix (results not shown).

\section{Discussion}

Nonadditive components of genetic variation make an important contribution to floral characters of M. guttatus. The null hypothesis that these components are zero $\left(C_{\mathrm{AD}}=0\right.$ and $\left.V_{\mathrm{DI}}=0\right)$ was rejected with a high level of confidence for four of the five traits $(P<0.01$ in each case; Table 2). These results are fully concordant with the only comparable study of a natural plant population. Shaw et al (1998) were able to reject $C_{\mathrm{AD}}=0$ and $V_{\mathrm{DI}}=0$ for each of the floral characters in their study of Nemophila menziesii. Of course, the evolutionary relevance of $C_{\mathrm{AD}}$ and $V_{\mathrm{DI}}$ depends not only on their magnitudes, but also on the level of inbreeding in the population. M. guttatus is a mixed mating species and the estimated selfing rate varies from 0 to 0.75 among populations (Ritland and Ganders, 1987; Willis, 1993; Awadalla and Ritland, 1997; Sweigart et al, 1999). As a consequence, we expect the nonadditive components to impact substantially evolutionary change in some populations but make only a minor contribution in others.

Floral morphology differs strikingly within the genus Mimulus and many studies have explored the genetic basis of this variation within and among species (Vickery, 1978; Macnair and Cumbes, 1989; Ritland and Ritland, 1989; Fenster and Ritland, 1994; Mossop et al, 1994; Bradshaw et al, 1995; Dudash and Carr, 1998; Schemske and Bradshaw, 1999; Willis, 1999a,b). Most directly relevant here are two quantitative genetic studies of floral variation within M. guttatus (Robertson et al, 1994; Carr and Fenster, 1994). Robertson et al (1994) detected significant additive genetic variation for corolla width, corolla length, pistil length, stigma-anther separation, and flowering time for a population native to California. However, the proportion of variation in corolla size that could be attributed to additive effects was substantially smaller than for the same traits in this study. In contrast, Carr and Fenster (1994) applied parent-offspring comparisons to plants derived from two other California populations and obtained estimates that were generally greater than those in Table 2. Differences in experimental methods prevent a rigorous statistical comparison of these studies (eg Shaw et al, 1995) and the confidence intervals are fairly broad. However, we suggest that the results probably reflect genuine differences in the level of genetic variability within local populations of M. guttatus.

This study departs from previous quantitative genetic experiments in its detailed consideration of genetic dominance. Robertson et al (1994) found evidence of dominance variation in some traits, but their study does not decompose this variation into components. The decomposition of nonadditive variation into $V_{\mathrm{D}}, C_{\mathrm{AD}}$, and $V_{\mathrm{DI}}$ is valuable because each component has distinct evolutionary implications. The standard dominance variance $V_{\mathrm{D}}$ does not contribute to selection response. 
In contrast, $C_{\mathrm{AD}}$ and $V_{\mathrm{DI}}$ are essential to evolutionary predictions for both the mean and the directional dominance of traits in an inbreeding population (Wright and Cockerham, 1985; Kelly, 1999a).

We have emphasized the effect of mating system on floral evolution, but the mating system is itself dependent on the characters considered in this study. Stigmaanther separation may often determine the amount of self-fertilization that occurs within a flower (Vasek, 1965; Robertson and Lloyd, 1991; Karron et al, 1997), although several studies of $M$. guttatus have failed to find a relationship (Robertson et al, 1994; Arathi et al, 2002). Corolla size (width and length) can influence the mating system by affecting the 'attractiveness' of flowers to pollinators (Galen et al, 1987) and thus the amount of foreign pollen that a plant is likely to receive (or to be visited at all). Finally, the amount and quality of pollen may influence visitation rates (Robertson et al, 1999) and pollen characteristics are genetically correlated with corolla size in this population of M. guttatus (Willis, 1999a). These observations suggest an interesting reciprocal interaction: response to selection on floral characters depends on the level of inbreeding, but this level is likely to change as floral characters evolve.

\section{Statistical issues}

There are a number of statistical issues associated with the estimation of these variance components that merit comment. The first regards the use of inbred lines as parents in a breeding design. The purpose of this experiment was to extract genetic parameter estimates that are informative about the Iron Mountain population of M. guttatus. Our implicit assumption is that allele frequencies among the 300 inbred lines are representative of allele frequencies in the natural population. While slight changes are inevitable owing to the finite number of lines and to Mendelian segregation during line formation, this source of randomness is accounted for in the statistical analysis. However, deterministic changes are assumed to be absent.

One potentially important deterministic bias is the loss of alleles that are lethal or cause sterility in homozygous form. Such lethal and sterile mutations would likely have been purged from the experimental population during line formation Willis (1999a) created these lines for exactly this purpose. If (1) a substantial number of lethal and/or sterile mutations are segregating in the Iron Mountain population and (2) such mutations typically have pleiotropic effects on floral traits, then biased parameter estimates may result. In particular, we would expect the experimental population to exhibit lower overall levels of genetic variation and a relatively lower contribution of the inbreeding components to that variation $\left(C_{\mathrm{AD}}\right.$ and $V_{\mathrm{DI}}$ will be reduced to a greater extent than $V_{\mathrm{A}}$ ). The former reflects the fact that lethals and steriles should have low population frequencies and be partially or completely recessive (Simmons and Crow, 1977). Such alleles make a greater contribution to $C_{\mathrm{AD}}$ and $V_{\text {DI }}$ (proportionally) than do alleles with intermediate frequencies (Kelly, 1999b).

Willis (1999a) found that lethals and/or steriles make a minority contribution to inbreeding depression in fitness-related traits. This suggests a limited contribution to genetic variation in floral traits for two reasons. First, because lethals and steriles should have lower frequencies and be more recessive than weakly deleterious mutations, their contribution to the genetic variance in fitness components will be smaller than their contribution to the inbreeding depression in these traits (in terms of the percent of each quantity explained). Second, it seems likely that their indirect contribution to floral traits (through pleiotropy) will be lower than their direct contribution to genetic variance of fitness traits.

Even in situations where lethals and steriles are an important source of variation, purging during line formation may be an advantage rather than a shortcoming of the experiment. The usual purpose of heritability studies is to measure the evolutionary potential of a population. While lethals and/or steriles may contribute to variability in a trait, they are not likely to contribute to adaptive evolution (Keightley and Hill, 1990). For this reason, the use of purging lines may actually provide a better representation of variation that is available to selection.

Linkage disequilibrium is a second concern for experiments based on inbred lines. Here, we used a large, random collection of lines as parents. Each was identified from a distinct field collected family. With this method of line formation, linkage disequilibria among QTL should be low and characteristic of that in the natural population. However, this may not be the case in many agricultural experiments. If the number of parental lines is limited, selected nonrandomly, or derived from populations with a history of artificial selection, substantial linkage disequilibrium is likely. Serious estimation bias can result if associations among loci are either consistently positive or consistently negative. Negative associations, which yield the phenomenon of associative overdominance, have been observed in studies of domestic corn (Moll et al, 1964; Lynch and Walsh, 1998, pp 604-605). Linkage disequilibria of this kind will bias $V_{\mathrm{A}}$ and $C_{\mathrm{AD}}$ downward and inflate $V_{\mathrm{D}}$. A comparable cascade of biases result if there are positive associations among loci. While a serious problem, these disequilibria can be greatly reduced by appropriate experimental design (involving repeated rounds of random mating).

\section{Inbreeding and genetic variance}

Finally, it is worth considering the results of this study in relation to the extensive literature on inbreeding and the variance of quantitative characters (Fowler and Whitlock (1999) provide references to many of these studies). Lerner (1954) argued that inbreeding causes the breakdown of developmental canalization. Highly homozygous genotypes should produce a greater range of phenotypes than comparable heterozygous genotypes. Experiments on a range of organisms provide some support for this idea (Wright, 1977; Pray and Goodnight, 1997) although the results vary substantially among studies (Fowler and Whitlock, 1999). Our results do suggest some breakdown of canalization with inbreeding (Table 2). The environmental variance was higher for inbred genotypes than outbred genotypes in four of five traits (significantly so for corolla width and stigmaanther separation). However, we do not have any evidence that this breakdown of canalization is detrimental to the organism. 
A more recent controversy concerns the quantitative effects of inbreeding and genetic drift that result from population bottlenecks. Several studies have noted an increase in the amount of additive genetic variation following a bottleneck (Bryant et al, 1986; Lopez-Fanjul and Villaverde, 1989; Fernandez et al, 1995; Wade et al, 1996), and this result has been interpreted as inconsistent with a purely additive model of inheritance. The additive model does predict that the expected additive variance will be lower after a bottleneck, but there should be substantial variability around this expectation (with $V_{\mathrm{A}}$ actually increasing in some replicates, eg Whitlock and Fowler, 1999). There is also debate about the kind of nonadditive genetic variation implied by elevated $V_{\mathrm{A}}$ in 'founder' populations. The result may reflect either the 'conversion' of epistatic variation into additive variation (Cockerham and Tachida, 1988; Goodnight, 1988; Meffert, 2000) or simply changes in the frequencies of rare, recessive alleles without any epistasis (Willis and Orr, 1993).

Analyses such as we employ here could be used to delineate between alternative nonadditive models. Each of the founder populations in these bottleneck experiments is essentially an extended family, not unlike those used in this study. Thus, if the relationships among individuals within a founder population are known, the entire dataset (measurements from all populations) can be used simultaneously to extract estimates for nonadditive components of genetic variation. Estimates for these components can then be used to test alternative models. For example, the rare recessives model predicts that $C_{\mathrm{AD}}$ should generally be greater than $V_{\mathrm{A}}$, and that $V_{\text {DI }}$ may be three or four times greater than $V_{\mathrm{A}}$ (Kelly, 1999b). Various epistatic models may also produce specific predictions for the expected resemblance of different classes of relatives. While such methods may seem elaborate, the inherent complexity of genetic architecture implies the need to bring all possible information to bear on the problem.

\section{Acknowledgements}

This paper benefited from reviews by $\mathrm{F}$ Shaw, $\mathrm{M}$ Whitlock, R Ramirez, S Williamson, N Slade, L Brandt, $\mathrm{B}$ Obbo, and several anonymous reviewers. The work was supported by NSF grant DEB 9903758.

\section{References}

Abney M, McPeek MS, Ober C (2000). Estimation of variance components of quantitative traits in inbred populations. $A m \mathrm{~J}$ Hum Genet 66: 629-650.

Arathi HS, Rasch A, Cox C, Kelly JK (2002). Autogamy and floral longevity in Mimulus guttatus. Int J Plant Sci 163: 567753.

Awadalla P, Ritland K (1997). Microsatellite variation and evolution in the Mimulus guttatus species complex with contrasting mating systems. Molecular Biology and Evolution 14: 1023-1034.

Beavis WD, Frey KJ (1987). Expression of nuclear-cytoplasmic interactions and heterosis in quantitative traits of oats (Avena spp.). Euphytica 36: 877-886. de Boer IJM, Hoeschele I (1993). Genetic evaluation methods for populations with dominance and inbreeding. Theor Appl Genet 86: 245-258.

Bradshaw HD, Wilbert SM, Otto KG, Schemske DW. (1995). Genetic mapping of floral traits associated with reproductive isolation in monkeyflowers (Mimulus). Nature 376: 762-765.

Bridges WC, Knapp SJ (1987). Probabilities of negative estimates of genetic variances. Theor Appl Genet 74: 269-274.

Brodie ED (2000). Why evolutionary genetics does not always add up. In: Wolf JB, Brodie ED, Wade MJ (eds). Epistasis and the Evolutionary Process, Oxford University Press: New York. pp 3-19.

Bryant EH, McCommas SA, Combs LM (1986). The effect of an experimental bottleneck upon the quantitative genetic variation in the house fly. Genetics 114: 1191-1211.

Carr DE, Fenster CB (1994). Levels of genetic variation and covariation for Mimulus (Scrophulariaceae) floral traits. Heredity 72: 606-618.

Clayton GA, Morris JA, Robertson A (1957). An experimental check on quantitative genetic theory. I. Short term responses to selection J Genet 5: 131-151.

Cockerham CC (1983). Covariances of relatives from selffertilization. Crop Sci 23: 1177-1180.

Cockerham CC, Matzinger DF (1985). Selection response based on selfed progenies. Crop science 25: 483-488.

Cockerham CC, Tachida H (1988). Permanency of response to selection for quantitative characters in finite populations. Proc Natl Acad Sci 85: 1563-1565.

Cockerham CC, Weir BS (1984). Covariances of relatives stemming from a population undergoing mixed self and random mating. Biometrics 40: 157-164.

Cornelius PL (1988). Properties of components of covariance of inbred relatives and their estimates in a maize population. Theor Appl Genet 75: 701-711.

Dudash MR, Carr DE (1998). Genetics underlying inbreeding depression in Mimulus with contrasting mating systems. Nature 393: 682-684.

Eliason SR (1993). Maximum Likelihood Estimation: Logic and Practice. Series: Quantitative Applications in the Social Sciences. Sage Publications: London.

Falconer DS (1989). An Introduction to Quantitative Genetics. John Wiley and Sons Co: New York.

Fenster CB, Galloway LF, Chao L (1997). Epistasis and its consequences for the evolution of natural populations. TREE 12: $282-286$

Fenster CB, Ritland K (1994). Quantitative genetics of mating system divergence in the yellow monkeyflower species complex. Heredity 73: 422-435.

Fernandez A, Toro MA, Lopez-Fanjul C (1995). The effect of inbreeding on the redistribution of genetic variance of fecundity and viability in Tribolium castaneum. Heredity 75: 376-381.

Fowler K, Whitlock MC (1999). The distribution of phenotypic variance with inbreeding. Evolution 53: 1143-1156.

Gallais A (1977). An experimental check of quantitative genetics on an autotetraploid plant, Medicago sativa, L., with special reference to the identity by descent relationship. In: Pollack OKE, Bailey TB (eds). Proceedings of the International Conference on Quantitative Genetics, Iowa State University Press: Ames, Iowa.

Galen C, Zimmer KA, Newport ME (1987). Pollination in floral scent morphs of Polemonium viscosum: a mechanism for disruptive selection on flower size. Evolution 41: 599-606.

Galloway LF, Fenster CB (2001). Nuclear and cytoplasmic contributions to intraspecific divergence in an annual legume. Evolution 55: 488-497.

Gillois M (1964). Calcul de coefficients d'identite d'apres les liens de parente. Commincation aux Journees d'etudes de la Commision de genetique de la federation europeenne de Zootechnie, Lisbonn. 
Goodnight CJ (1988). Epistasis and the effect of founder events on the additive genetic variance. Evolution 42: 441-454.

Grant PR, Grant BR (1995). Predicting microevolutionary responses to directional selection on heritable variation. Evolution 49: 241-251.

Harris DL (1964). Genotypic covariances between inbred relatives. Genetics 50: 1319-1348.

Karron JD, Jackson RT, Thumser NN, Schlicht ST (1997). Outcrossing rates of individual Mimulus ringens genets are correlated with anther-stigma separation. Heredity 79: 365-370.

Keightley PD, Hill WG (1990). Variation maintained in quantitative traits with mutation selection balance: pleiotropic side effects on fitness traits. Proc R Soc Lond B 242: 95-100.

Kelly JK (1999a). Response to selection in partially self fertilizing populations. I. Selection on a single trait. Evolution 53: 336-349.

Kelly JK (1999b). An experimental method for evaluating the contribution of deleterious mutations to quantitative trait variation. Genet Res 73: 263-273.

Kelly JK, Williamson S (2000). Predicting response to selection on a quantitative trait: a comparison between models for mixed-mating populations. J Theor Biol 207: 37-56.

Kelly JK, Willis JW (2001). Deleterious mutations and genetic variation for flower size in Mimulus guttatus. Evolution 55: 937-942.

Lerner IM (1954). Genetic Homeostasis. Oliver and Boyd: Edinburgh.

Lopez-Fanjul C, Villaverde A (1989). Inbreeding increases genetic variance for viability in Drosophila melanogaster. Evolution 43: 1800-1804

Lynch M, Walsh B (1998). Genetics and Analysis of Quantitative Characters. Sinauer Associates: Sunderland, MA

Macnair MR, Cumbes QJ (1989). The genetic architecture of interspecific variation in Mimulus. Genetics 122: 211-222.

Meffert LM (2000). The evolutionary potential of morphology and mating behavior: the role of epistasis in bottlenecked populations. In: Wolf JB, Brodie ED, Wade MJ (eds). Epistasis and the Evolutionary Process, Oxford University Press: New York. pp 177-193.

Mitchell-Olds T, Rutledge JJ (1986). Quantitative genetics in natural plant populations: A review of the theory. Am Nat 127: 379-402.

Moll RH, Lindsey MF, Robinson HF (1964). Estimates of genetic variances and level of dominance in Maize. Genetics 49: 411-423.

Mossop R, Macnair MR, Robertson AW (1994). Within population variation in sexual resource allocation in Mimulus guttatus. Funct Ecol 8: 410-418.

Mousseau TA, Roff DA (1987). Natural selection and the heritability of fitness components. Heredity 59: 181-197.

Pederson DG (1969). The prediction of selection response in a self-fertilizing species I. Individual selection. Australian Journal of Biological Science 22: 117-129.

Pray LA, Goodnight CJ (1997). The effect of inbreeding on the phenotypic variance in the red flour beetle Tribolium castaneum. Evolution 51: 308-313.

Rice JA (1989). Mathematical Statistics and Data Analysis. Wadsworth and Brooks: Pacific Grove, CA.

Ritland K, Ganders FR (1987). Covariation of selfing rates with parental gene fixation indexes within populations of Mimulus guttatus. Evolution 41: 760-771.

Ritland C, Ritland K (1989). Variation of sex allocation among eight taxa of the Mimulus guttatus species complex (Scrophulariaceae). Am J Bot 76: 1731-1739.

Robertson A (1952). The effect of inbreeding on the variation due to recessive genes. Genetics 37: 189-207.

Robertson AW, Diaz A, MacNair MR (1994) The quantitative genetics of floral characters in Mimulus guttatus. Heredity 72: 300-311.

Robertson AW, Lloyd DG (1991). Herkogamy, dichogamy and self-pollination in six species of Myosotis (Boraginaceae). Evol Trends Plants 5: 53-63.

Robertson AW, Mountjoy C, Faulkner BE, Roberts MV, Macnair MR (1999). Bumble bee selection of Mimulus guttatus flowers: the effects of pollen quality and reward depletion. Ecology $\mathbf{8 0}$ 2594-2606.

Roff DA (1997). Evolutionary Quantitative Genetics. ChapmanHall: New York.

Searle SR, Casella G, McCulloch CE (1992). Variance Components. John Wiley and Sons Inc.: New York.

Schemske DW, Bradshaw HD (1999). Pollinator preference and the evolution of floral traits in monkey flowers (Mimulus). Proc Natl Acad Sci USA 96: 11910-11915.

Self SG, Liang KY (1987). Asymptotic properties of maximum likelihood estimators and likelihood ratio tests under nonstandard conditions. I Am Stat Assoc 82: 605-610.

Shaw FH, Shaw RG, Wilkinson GS, Turelli M (1995). Changes in genetic variances and covariances: $G$ whiz. Evolution 49: 1260-1267.

Shaw FH, Woolliams JA (1999). Variance component analysis of skin and weight data for sheep subjected to rapid inbreeding. Genet, Selection, and Evol 31: 43-59.

Shaw RG (1987). Maximum-likelihood approaches applied to quantitative genetics of natural populations. Evolution 41: 812-826.

Shaw RG, Byers DL, Shaw FH (1998). Genetic components of variation in Nemophila menziesii undergoing inbreeding: morphology and flowering time. Genetics 150: 1649-1661.

Simmons MJ, Crow JF (1977). Mutations affecting fitness in Drosophila populations. Ann. Rev. Genet. 11: 49-78.

Sweigart A, Karoly K, Jones A, Willis JH (1999). The distribution of individual inbreeding coefficients and pairwise relatedness in a population of Mimulus guttatus. Heredity 83: 625-632.

Vasek FC (1965). Outcrossing in natural populations. II. Clarkia unguiculata. Evolution 19: 152-156.

Vickery RK (1978). Case studies in the evolution of species complexes in Mimulus. Evol Biol 11: 405-507.

Wade MJ (1992). Sewall Wright: gene interaction and the shifting balance theory. Oxford Surveys Evol Biol 8: 35-62.

Wade MJ, Schuster SM, Stevens L (1996). Inbreeding: its effect on response to selection for pupal weight and the heritable variance in fitness in the flour beetle, Tribolium castaneum. Evolution 50: 723-733.

Whitlock MC, Fowler K (1999). The changes in the genetic and environmental variance with inbreeding in Drosophila melanogaster. Genetics 152: 345-353.

Willham RL (1963). The covariance between relatives for characters composed of components contributed by related individuals. Biometrics 19: 18-27.

Willis JH (1993). Partial self fertilization and inbreeding depression in two populations of Mimulus guttatus. Heredity 71: 145-154.

Willis JH (1996). Measures of phenotypic selection are biased by partial inbreeding. Evolution 50: 1501-1511.

Willis JH (1999a). The role of genes of large effect on inbreeding depression in Mimulus guttatus. Evolution 53: 1678-1691.

Willis JH (1999b). Inbreeding load, average dominance, and the mutation rate for mildly deleterious alleles in Mimulus guttatus. Genetics 153: 1885-1898.

Willis JH, Orr HA (1993). Increased heritable variation following population bottlenecks: the role of dominance. Evolution 47: 949-957.

Wright AJ (1987). Additive variance and average effect with partial selfing. Genet Res 50: 63-68.

Wright AJ, Cockerham CC (1985). Selection with partial selfing. I. Mass selection. Genetics 109: 585-597.

Wright S (1951). The genetical structure of populations. Ann Eugenics 15: 323-354.

Wright S (1952). The genetics of quantitative variability. In: Reeve ECR, Waddington $\mathrm{CH}$ (eds). Quantitative Inheritance, pp. 5-41.

Wright S (1977). Evolution and the Genetics of Populations, Vol. 3. Experimental Results and Evolutionary Deductions. University of Chicago Press: Chicago. 